\title{
Uncovering cognitive processes: Different techniques that can contribute to cognitive load research and instruction
}

Citation for published version (APA):

Van Gog, T., Kester, L., Nievelstein, F., Giesbers, B., \& Fred, P. (2009). Uncovering cognitive processes: Different techniques that can contribute to cognitive load research and instruction. Computers in Human Behavior, 25(2), 325-331. https://doi.org/10.1016/j.chb.2008.12.021

DOI:

10.1016/j.chb.2008.12.021

Document status and date:

Published: 01/03/2009

Document Version:

Peer reviewed version

Please check the document version of this publication:

- A submitted manuscript is the version of the article upon submission and before peer-review. There can be important differences between the submitted version and the official published version of record. People interested in the research are advised to contact the author for the final version of the publication, or visit the DOI to the publisher's website.

- The final author version and the galley proof are versions of the publication after peer review.

- The final published version features the final layout of the paper including the volume, issue and page numbers.

Link to publication

\section{General rights}

Copyright and moral rights for the publications made accessible in the public portal are retained by the authors and/or other copyright owners and it is a condition of accessing publications that users recognise and abide by the legal requirements associated with these rights.

- Users may download and print one copy of any publication from the public portal for the purpose of private study or research.

- You may not further distribute the material or use it for any profit-making activity or commercial gain

- You may freely distribute the URL identifying the publication in the public portal.

If the publication is distributed under the terms of Article 25fa of the Dutch Copyright Act, indicated by the "Taverne" license above, please follow below link for the End User Agreement:

https://www.ou.nl/taverne-agreement

Take down policy

If you believe that this document breaches copyright please contact us at:

pure-support@ou.nl

providing details and we will investigate your claim.

Downloaded from https://research.ou.nl/ on date: 26 Apr. 2023 
Running head: UNCOVERING COGNITIVE PROCESSES

This is a pre-print of:

Van Gog, T., Kester, L., Nievelstein, F., Giesbers, B., \& Paas, F. (2009). Uncovering cognitive processes: Different techniques that can contribute to cognitive load research and instruction. Computers in Human Behavior, 25, 325-331.

Copyright Elsevier, available online at: http://www.elsevier.com/wps/find/journaldescription.cws_home/759/description\#description

Uncovering Cognitive Processes: Different Techniques that Can Contribute to Cognitive Load Research and Instruction

Tamara van Gog ${ }^{\mathrm{a}}$, Liesbeth Kester ${ }^{\mathrm{a}}$, Fleurie Nievelstein ${ }^{\mathrm{a}}$, Bas Giesbers ${ }^{\mathrm{a}}$, and Fred Paas ${ }^{\mathrm{a}, \mathrm{b}}$

${ }^{\text {a }}$ Educational Technology Expertise Center, Open University of The Netherlands

${ }^{\mathrm{b}}$ Psychology Department, Erasmus University Rotterdam, The Netherlands

Author Note

Correspondence concerning this article should be addressed to Tamara van Gog, Educational Technology Expertise Center, Open University of The Netherlands, P.O. Box 2960, 6401 DL Heerlen, The Netherlands. T: +31 45 5762276, F: +31 45 5762907, E: tamara.vangog@ou.nl

Bas Giesbers is now at the Faculty of Economics and Business Administration, Maastricht University.

Acknowledgement. During the realization of this work, Liesbeth Kester was supported by a Veni Grant from the Netherlands Organization for Scientific Research (project nr. 016075-121). 


\begin{abstract}
This article discusses the use of different techniques for uncovering cognitive processes, for research and instructional purposes: verbal reporting, eye tracking, and concept mapping. It is argued here that applying these techniques in research inspired by Cognitive Load Theory may increase our understanding of how and why well-known effects of instructional formats come about (e.g., split-attention, redundancy, or worked example effects) and refine or corroborate the proposed theoretical underpinnings of such effects. This knowledge can inform instructional design, and moreover, the effects of these techniques on learning can also be direct, by embedding the techniques in instruction.
\end{abstract}

Keywords: cognitive load, verbal reports, eye tracking, concept mapping, example-based learning 
Uncovering Cognitive Processes: Different Techniques That Can Contribute to Cognitive Load Research and Instruction

Research on instructional design inspired by Cognitive Load Theory (CLT; Sweller, 1988; Sweller, Van Merriënboer, \& Paas, 1998; Van Merriënboer \& Sweller, 2005) usually includes assumptions on cognitive processes evoked by instruction that help or hinder schema acquisition. However, most often these assumptions are only tested by relatively indirect measures such as test performance data. It is argued here that directly studying cognitive processes during task performance and/or acquired cognitive structures after task performance can provide valuable information on how the effects of different instructional formats occur.

For example, CLT research has shown that split-attention instructional formats, such as separately presented but mutually referring text and diagrams, hamper learning, whereas integrated or multiple modality formats foster learning (Chandler \& Sweller, 1991, 1992; Tindall-Ford, Chandler \& Sweller, 1997; see also Cierniak, Scheiter, \& Gerjets, this issue). However, how these different instructional formats affect information processing and thereby learning is seldom studied directly, although there are many different ways in which learners can process for example text and diagrams (an exception is the study by Hegarty \& Just, 1993, and some very recent studies, described in more detail in the section Eye Movements for Studying Cognitive Processes). For instance, they might first read the entire text, then look at the diagram, or look at the diagram every time a component is mentioned in the text, or first read a portion of text and then look at the diagram to verify understanding, et cetera (see also Hegarty \& Just, 1993). Studying the way in which learners interact with text and diagrams in split-attention and integrated formats could show how and why the split-attention effect occurs, that is, exactly what process(es) lead to the extraneous load that hampers learning.

Next to providing more insight into how certain effects of instructional formats come about, more direct investigations of cognitive processes and acquired cognitive structures are 
also necessary for CLT to continue to extend its scope towards instructional design for advanced learners and the enabling of effective personalized instructional paths (see also Van Gog, Ericsson, Rikers, \& Paas, 2005). When a learner's knowledge base changes, these changes influence the effectiveness of instructional formats during future learning. Hence, techniques to accurately judge the content of this knowledge base will help to adapt the instruction to the learner's needs (cf. Kalyuga, 2006a, b).

From a practical perspective, research using more direct investigations of cognitive processes and acquired cognitive structures can inform the design of more effective instructional materials and strategies (relatively indirect application). Moreover, techniques that uncover cognitive processes for researchers, can also do so for learners, which implies that these techniques might also be used directly to stimulate learning. For each of the three techniques discussed here, that is, verbal reporting, eye tracking, and concept mapping, the technique and the kind of information it elicits are first explained from a research perspective, then its potentials for learning and instruction are described.

\section{Verbal Reporting}

\section{Verbal Reports for Studying Cognitive Processes}

The two most widely used verbal reporting techniques are concurrent and retrospective reporting. Concurrent reporting (Ericsson \& Simon, 1993; Van Someren, Barnard, \& Sandberg, 1994) requires learners to verbalize all thoughts that come to mind during task performance. Retrospective reporting (Ericsson \& Simon, 1993) on the other hand, requires learners to report the thoughts they had while they were working on a task immediately after task performance. Both techniques allow for valid inferences about the cognitive processes underlying task performance when the verbalization instructions and prompts are worded in such a way that the evoked responses do not interfere with the cognitive processes (e.g., learners should not be asked to reflect, explain or elaborate; see 
Ericsson \& Simon, 1993, for information on appropriate instructions and prompts). An additional requirement for retrospective reporting to allow valid inferences is that task duration needs to be very short. On longer tasks there is a risk that information is omitted (i.e., thoughts that were present during task performance are not reported) or constructed (i.e., thoughts are being reported that were not actually there during task performance).

It has also been suggested that concurrent and retrospective reporting result in different types of information about cognitive processes. For example, according to Taylor and Dionne (2000), concurrent protocols seem to provide more information on actions and outcomes than retrospective reports, which seem to provide more information about strategies and conditions for actions than concurrent reports. Kuusela and Paul (2000) also reported that concurrent protocols contained more information on actions than retrospective protocols, arguing that retrospective reports often only contained references to the effective actions that led to the solution.

Both the risk of omission and construction in retrospective reporting, and the findings that concurrent and retrospective reporting seem to result in different types of information, seem to be related to the time at which the report is generated (during or after task performance). That is, the techniques rely on different memory systems. Whereas concurrent reports capture information available in working memory during the task performance process, retrospective reports require retrieval of memory traces of the task performance process from long-term memory when tasks are of longer duration (Camps, 2003; Ericsson \& Simon, 1993; for a more detailed explanation of how this may affect information present in the reports, see Van Gog, Paas, Van Merriënboer, \& Witte, 2005).

The fact that concurrent reporting relies on working memory, may also have drawbacks. First of all, concurrent reporting may become difficult to maintain under high cognitive load conditions (Ericsson \& Simon, 1993). Indeed, participants in the study by Van 
Gog, Paas, Van Merriënboer, and Witte (2005) who experienced a high cognitive load during task performance (measured by self-reported investment of mental effort) indicated during a debriefing after the experiment that they disliked concurrent reporting and preferred cued retrospective reporting (see Van Gog, 2006). So, with novice learners or with highly complex tasks, concurrent reporting might not be the most optimal technique. Secondly, a lot of cognitive load research focuses on multimedia learning. On multimedia tasks that contain the same modality that the report draws on, reporting will interfere with information processing. For example, when instructional animations contain audio (spoken text, music, etc.), either concurrent reporting or understanding of the auditory information will be potentially compromised.

For these reasons, Van Gog, Paas, Van Merriënboer, and Witte (2005) were looking for a method that did not have the drawbacks of concurrent and retrospective reporting. They proposed that cued retrospective reporting, in which a retrospective report is cued by a replay of a record of eye movements and mouse/keyboard operations made during the task (for an impression, see Figure 1), might be a good candidate: Due to the retrospective nature of the report, problems of cognitive overload would not occur, whereas due to the cue, less omissions and constructions of actions would be expected than in 'regular' retrospective reporting. The presence of mouse and keyboard operations could stimulate reporting of thoughts regarding physical actions, whereas the added value of eye movements in the cue, is that they could trigger reporting of thoughts regarding purely cognitive actions.

Apart from being a useful research tool, verbal reporting techniques can also be directly or indirectly applied in the design of instruction.

\section{Verbal Reports in Instruction}

First of all, verbal reports of 'experts' could be used to design instruction. Learning by observing and/or imitating expert examples is a powerful learning strategy (Bandura, 1986). 
Cognitive load research has shown that worked examples, in which students can study a written account of an expert's solution procedure, or process-oriented worked examples, in which the rationale behind the procedure is also made explicit, is very effective for novices (Van Gog, Paas, \& Van Merriënboer, 2006, 2008; and for reviews of worked examples research Atkinson, Derry, Renkl, \& Wortham, 2000; Sweller et al., 1998). The information to include in those examples can be obtained from verbal reports of experts (i.e., indirect use). Another option is not to provide students with a written account, but to use video-based or real-life modelling examples (cf., Zimmerman \& Kitsantas, 2002; see also Wouters, Paas, \& Van Merriënboer, 2008), in which students can observe the expert solving the problem while simultaneously verbalizing his/her thoughts (i.e., direct use of verbal reports).

It is important to note here, though, that expert is defined in different ways by different authors, and can mean someone who is good at performing a task, someone who has a lot of experience in a domain, or a teacher. 'Experts' as domain experts have a knowledge base that differs enormously from that of students both in magnitude and in organization, and they have developed automated procedures for solving routine problems in their domain (see Chi, Glaser, \& Farr, 1988; Ericsson, Charness, Feltovich, \& Hoffman 2006). Feldon (2007) showed that such experts' self-reports are often suboptimal for instructional use, because automation may result in omissions. 'Experts' as good task performers, however, can also be well-performing students who are somewhat more advanced of the goal population, or teachers who are used to performing the task in the way it is taught to students. Verbal protocols of these 'experts', who have not yet automated performance procedures, are much closer to the knowledge base of the goal population of learners and could therefore be more effective.

Secondly, verbal reports generated by students themselves during instruction, may also enhance learning. For example, asking students to self-explain solution steps in worked 
examples or their own solution steps is known to enhance their understanding (Chi, De Leeuw, Chiu, \& LaVancher, 1994). However, if students are not able to generate selfexplanations, because they lack the necessary knowledge and as a consequence experience a high cognitive load imposed by the task, requiring them to self-explain may not help or even hinder learning (that is, rather than imposing germane load, it may lead to extraneous load for some learners). Moreover, self-explanations, however, are not always of the same nature/quality, which seems to be the determinant of effects on learning (Renk1, 1997). To enhance the quality of self-explanations, prompts can be used. For example, Atkinson, Renkl, and Merrill (2003) designed prompts to encourage learners to identify the underlying principles illustrated in worked-out solution steps, which resulted in beneficial effects on transfer test performance.

An important difference between the use of verbal reports as a research tool and as an instructional tool is the instruction given. As mentioned above, whereas the reporting instruction should be as neutral as possible in research, to ensure that the thought processes are not influenced, this is not a problem in instructional situations, where influencing thought processes is helpful when this leads to better learning. Another difference is that in instruction, verbal reports could also take the form of written text.

$$
\text { Eye Tracking }
$$

\section{Eye Movements for Studying Cognitive Processes}

Eye tracking, that is, recording an individual's eye movements (see Duchowski, 2003), is suited for studying cognitive processes and processing demands (i.e., cognitive load) at a detailed level. Eye fixation data reflect attention and shifts in attention, so these may be very helpful in investigating the split-attention or modality effects in particular. For example, Hegarty and Just (1993) conducted an eye-tracking study on learning from text and diagrams. They only studied a split-format, but their study shows how informative eye tracking data can 
be regarding how learners read and re-read text, when they switch from the text to the diagram and vice versa, and how they inspect the diagram. Recent studies have compared the effects of different formats (e.g., split vs. integrated, sequential vs. radial) in terms of visual attention allocation (eye movements), and show how this technique can increase our insight into how these formats affect viewing behaviour, which in turn influences learning (e.g., Holsanova, Holmqvist, \& Holmberg, 2008; Schmidt-Weigand, Kohnert, \& Glowalla, 2008).

Some environmental features will draw attention automatically (i.e., exogenous shifts), for example, when something brightly coloured would start flashing in the corner of your computer screen while you are working, your attention will be drawn to it. However, attention shifts can also occur voluntarily, that is, driven by knowledge of the task, of the environment, and of the importance of available information sources (i.e., endogenous shifts; see Stelmach, Campsall, \& Herdman, 1997; Underwood, Chapman, Brocklehurst, Underwood, \& Crundall, 2003). The influence of prior knowledge or expertise on eye movements has been demonstrated in several studies: with increasing knowledge of a task, individuals fixate more on task-relevant information (Haider \& Frensch, 1999), and it seems that this is not only the case when comparing experts to novices (e.g., Charness, Reingold, Pomplun, \& Stampe, 2001), but may also be found with smaller differences in expertise levels (Van Gog, Paas, \& Van Merriënboer, 2005). Therefore, eye movement data may also be useful for studying differences in cognitive processes between different expertise levels or changes in cognitive structures at an individual level over time. In particular it could provide more insight into the nature of expertise-reversal effects, which show that some instructional formats that are effective for novices (e.g., integrated text and diagram; worked examples), are not effective, or may even hamper learning for advanced students (see for an overview Kalyuga, Ayres, Chandler, \& Sweller, 2003). 
Eye movement data can provide other information particularly important for CLT research, namely regarding processing demands, or in other words, cognitive load. For example, pupil dilation (see e.g., Van Gerven, Paas, Van Merriënboer, \& Schmidt, 2004), and fixation duration are known to increase with increased processing demands, whereas the length of saccades (movement of the eyes in between fixations) decreases (for an in-depth discussion of eye movement data and cognitive processes, see Rayner, 1998). However, although fixation duration can be considered a measure of cognitive load, it does seem to measure a different aspect of this construct than mental effort ratings. For example, both Amadieu, Van Gog, Paas, Tricot, and Mariné (2007) and Van Gog, Paas, and Van Merriënboer (2005), found that individuals who reported to invest less mental effort overall had a higher mean fixation duration in certain phases of the task than those who reported to have invested more mental effort. Of course, this difference may be an artefact of the fact that mental effort measures are usually overall task/process measures (for an exception, see Ayres, 2006), whereas mean fixation duration data are usually computed for parts of a task/process. Nonetheless, it may also be the case that the measures really reflect different aspects of cognitive load, because experiencing an overall lower load (as reflected by lower mental effort scores), might allow one to allocate more cognitive capacity to processing information in the learning task, thereby leading to higher fixation duration. It would therefore be interesting for CLT researchers to study how processing demands as measured by fixation duration fluctuate in different phases of the learning process and how these patterns are related to overall cognitive load and investment of mental effort.

Next to providing a useful tool to investigate effects of instructional formats in more detail, as well as fluctuations in cognitive load, records of eye movements can also have more direct applications in (the design of) instruction. 
Because attention allocation can be influenced by expertise as described above, eye tracking may also be applied to enhance worked examples or expert-modelling examples. It has been proposed that their effectiveness can be further improved by incorporating the eye movements of the expert (Van Gog, 2006). Because advanced students and experts are far more able than novices to decide what to attend to (relevant information) and what to ignore (irrelevant information; e.g., Haider \& Frensch, 1999; Van Gog et al., 2005), there will likely be a discrepancy in attention allocation between the expert on whom the example is based and the novice studying the example. Because attention allocation is reflected in a person's eye movements, including expert eye movements in modelling examples could diminish this discrepancy, because they could guide the learner's attention in an efficient way throughout the problem solving process. An integrated record could be made of a screen capture of the expert performing the task with an overlay of his/her eye movements (cf. the cue used in cued retrospective reporting; see Figure 1). Findings by Velichkovsky (1995) on cooperative problem solving by expert-novice pairs, using eye movements to demonstrate on which task aspects the partners focused their attention, support the assumption that attention can be guided via eye movements. The question remains, however, whether this could also enhance learning outcomes.

Another possibility would be to not show the eye movements directly as these tend to be very fast and may include too much 'noise', but dynamically cue or highlight the areas to which the expert successively devotes attention (cf. Grant \& Spivey, 2003). Especially in combination with process-oriented worked examples that also explicate the thought processes, such forms of attention guidance might help learners to better attend to and encode the relevant information in the examples.

In addition, the findings by Van Gog, Paas, Van Merriënboer, and Witte (2005) suggest that records of eye movements might also stimulate reflection. Cued retrospective 
reporting resulted in a higher number of metacognitive comments (e.g., statements about the adequacy of the learner's own knowledge, actions, or strategies) than concurrent and retrospective reporting. Although the difference was significant, the actual number of such statements in cued retrospective reporting was not very high. However, it should be noted that the reporting instructions used were neutral. Prompting students to reflect on task performance based on a record of eye movements either from themselves or from another student (the latter can be implemented during instruction, as they can be prepared in advance; the former is more difficult with the current technology) might positively affect their learning.

\section{Concept Mapping}

\section{Concept Maps for Studying Cognitive Structures}

Concept-mapping techniques require learners to make their knowledge of concepts and the relationships between concepts explicit, thereby reflecting the amount and organization of conceptual, structural and functional knowledge- in other words, they represent learners' cognitive schemata concerning a certain topic (Trochim, 1989). Conceptual knowledge describes and classifies the concepts (i.e., objects, events and ideas) in a particular domain (knowing what), and includes the part-of, kind-of, example-of, analogousto and prerequisite-for relations between concepts. Structural knowledge refers to the location-in-time and location-in-space relations between concepts (knowing how), and functional knowledge concerns causal and correlational relations between concepts (knowing why; Van Merriënboer, 1997). There are many different types of concept mapping tasks, that can differ not only in the type of relations depicted, but also in the degree of freedom provided (structuredness), and in the physical form (cards, drawings, computer software, etc.).

The difference between concept maps lies mainly in the kind of relations between concepts they depict (see Figure 2). Whereas semantic concept maps allow for the use of any meaningful relation, hierarchical and sequential/causal maps support only the depiction of that 
single type of relation (i.e., hierarchical or causal, respectively; see e.g., Robinson, 1998; Spector, Christensen, Sioutine, \& McCormack, 2001). The freedom provided by a concept mapping task depends not only on the kind of relationships one is allowed to draw, but also on whether the use of concepts is freely determined by the learner or whether a set of concepts to use is provided as in a card sort task for example (see De Jong \& Ferguson-Hessler, 1986; Nievelstein, Van Gog, Boshuizen, \& Prins, in press; Stoyanov \& Kirschner, 2004; Trochim, 1989; Wopereis, Kirschner, Paas, Stoyanov, \& Hendriks, 2005).

The freedom provided to learners in constructing a concept map, has important consequences for analysis of those maps and conclusions that can be drawn. When learners are free in selecting the relations and/or the concepts they use to draw a map, there may be large differences, for example, in the number of relations or concepts used and in the terminology used to refer to a certain concept (i.e., synonyms are possible). This will make it difficult to meaningfully compare concept maps of different individuals or groups (Johnson \& O'Connor, in press). However, comparisons with previous maps of the same learner may be less problematic (Schvaneveldt, Durso, Goldsmith, Breen, Cooke, Tucker, \& DeMaio, 1985). Analysis of differences between individuals or groups may be easier when a set of relations or concepts is given. But still, learners' interpretation of concepts may differ, and more importantly, they may recognize concepts more easily than they could generate them. In other words, they may be able to relate concepts to existing schemata when confronted with them, but these concepts may not be part of their own schema yet. So, concept maps based on predefined relations or concepts may not as accurately reflect someone's knowledge as concept maps drawn without such restrictions.

In sum, concept mapping techniques are suitable for assessing the content and quality of cognitive structures (schemata) before and after an instructional intervention, both at an individual and a group level. Because concept maps make the concepts and relations 
contained in cognitive schemata explicit, they can be a useful assessment tool for CLT research. For example, concept mapping could give us a more direct indication of the effects on acquisition or elaboration of cognitive schemata of instruction consisting of studying worked examples versus solving problems (e.g., Cooper \& Sweller, 1987; Sweller \& Cooper, 1985). The freedom allowed in constructing the concept map should depend on the importance of how accurate the individual knowledge has to be represented and how much time there is available for analysis

\section{Concept Maps in Instruction}

By making cognitive structures explicit, concept maps can also be used as an instructional and learning tool in three ways. First, ideal or expert concept maps can be used as a support tool that helps learners deal with instructional content (see also Hilbert \& Renkl, this issue). For example, hypertext learning environments allow learners to navigate freely through instructional content and actively construct their knowledge (Hannafin \& Land, 1997). The non-linear nature of these environments provides a high degree of freedom, as well as just-in-time information access, which can facilitate learning (i.e., through schema construction and schema automation; Kester, Kirschner, van Merriënboer, \& Bäumer, 2001). At the same time, however, this could hamper learning due to extraneous load imposed by (1) navigating through hypertext, which is often disorienting for learners and (2) trying to understand the non-linear information, which could cause high extraneous load because learners must structure this information themselves while concurrently solving the problem (Müller-Kalthoff \& Möller, 2003). Providing concept maps that reflect an ideal or expert conceptual organization of the content as a start page for hypertext learning environments could minimize both disorientation and cognitive overload, thereby resulting in better learning (McDonald \& Stevenson, 1998). However, it should be noted that the effectiveness of such maps seems to be mediated by the type of relations depicted and the level of expertise or prior 
knowledge of the learner (Amadieu et al., 2007; Potelle \& Rouet, 2003).

Concept mapping has been successfully applied as a learning tool to enhance both individual and collaborative learning (see meta-analyses of Horton, McConny, Gallo, Woods, \& Hamelin, 1993; Nesbit \& Adesope, 2006). Constructing a concept map in itself has beneficial effects on learning. A concept map is a type of graphic organizer and from several reviews in the graphic organizer literature it becomes clear that learners learn more from a text if they are asked to construct a graphic organizer to represent what they read as compared to learners who are presented with a graphic organizer that summarizes what they read (see Dunston, 1992, for an overview). This may be because learners more actively process the information in the text, or because explicating their knowledge in a concept map enables them to reflect on the text and reorganize their knowledge structures. Either way, these processes seem to impose a germane load that is effective for learning.

Concept mapping can also stimulate collaborative learning, because making the knowledge structures of each partner explicit can foster negotiation of meaning (see e.g., Johnson \& O’Connor, in press; O'Connor, Johnson, \& Khalil, 2004; Roth \& Roychoudhury, 1992, 1993; Van Boxtel, Van der Linden, Roelofs, \& Erkens, 2002). A review of 39 studies on collaborative concept mapping (CCM; Basque \& Lavoie, 2006) showed that the beneficial effects of CCM on performance (i.e., map quality) depend on learner characteristics (e.g., motivation), CCM-tool characteristics (e.g., task-specificity) or situational characteristics (e.g., face-to-face vs. distance). The review indicates that CCM is more effective in terms of performance for highly motivated students, task-specific tools and face-to-face situations. Furthermore, the effects of CCM on learning (i.e., performance on achievement, problemsolving or comprehension tests) were evaluated. Based on the studies that compared CCM with individual concept mapping or other collaboration techniques it was concluded that CCM was most beneficial for learning. 


\section{Discussion}

Although all three techniques -verbal reporting, eye tracking, and concept mappinguncover cognitive processes or acquired cognitive structures, it should be clear from the above that there are differences in the kind of information they elicit, that is, different techniques tap into different processes/structures or different aspects or levels of processes/structures. This, however, makes it interesting to combine techniques. But even though they are more direct measures than test performance for example, these techniques still require inferences from the researcher regarding cognitive processes, processing demands, or acquired cognitive structures, which poses different challenges for analysis.

Eye tracking provides mainly information on visual attention, and relating visual attention to cognitive processes should be done with great caution, because there is not always a one-to-one relationship (e.g., exogenous shifts in attention may occur unintentional). Using eye tracking in combination with either concurrent or cued retrospective verbal protocols, might provide more indications regarding underlying cognitive processes, that is, why a participant looks at something at a certain moment. The same goes for concept mapping, which also provides hardly any information about why learners group or relate concepts together, making a combination with verbal reporting useful (see e.g., Nievelstein et al., in press). Then again, making inferences about cognitive processes from verbal reports is not always straightforward either. Researchers might therefore be tempted to use interviews or self-explaining rather than concurrent, retrospective or cued retrospective reporting, because it provides them with exactly the kind of information they are interested in. However, as mentioned before, the instruction to answer questions or explain might lead to constructions (i.e., reporting of information that was not actually part of the process).

At present, analysis of the information gained with all three techniques can be timeconsuming. It is certainly not fast enough at present to be applied in adaptive, personalized 
instructional systems: When each subsequent instructional intervention depends on a previous assessment, a rapid assessment method is required (cf. Kalyuga, 2006a, b). All three techniques could in principle be used in such assessments, provided the right technology was available.

For verbal reports, when they are written or can be rapidly converted from spoken to written text, and for concept mapping, when concepts are labeled or annotated, latent semantic analysis (LSA; Landauer, \& Dumais, 1997, Landauer, McNamara, Dennis, Kintsch, 2007) might be a promising technique for rapid analysis. LSA is a technique for document comparison by representing documents as text vectors (Landauer et al., 2007). The vector representation of a corpus of texts in the same language allows a computer to "learn the language', that is, to calculate a representation of the relationship between words. A vector representation of a query document, such as a concept map or verbal protocol, can be compared to the corpus, but also to one or more defined standard documents or 'gold standards', such as an 'ideal' or 'expert' concept map or protocol (Foltz, 1996; Foltz, Gilliam, \& Kendall, 2000). LSA has been successfully applied in judging students' written responses to (tutor) questions in order to provide adaptive feedback (Foltz et al., 2000; Graesser, Wiemer-Hastings, Wiemer-Hastings, Harter, Person, \& the TRG, 2000), and a study by Wolfe et al. (1998) shows great promise for using it in adaptive task selection (for recent overviews of instructional applications of LSA, see Iofciu, Zhou, Giesbers, Rusman, Van Bruggen \& Ceri, 2006; Landauer et al., 2007). Apart from required technological advances, though, more research would be required for all three techniques to determine which algorithms for adaptive task selection would be sensible from a theoretical perspective (i.e., establishing how certain viewing patterns or concept patterns can be taken to reliably indicate a certain level of knowledge or performance). 
In general, advancements in technology for analysis of verbal protocol, eye movement, and concept mapping data could stimulate a wider use of these techniques in CLT research. As we have argued here, these techniques have the potential to increase our understanding of how and why well-known effects of CLT-based instructional formats come about. This may help us refine or corroborate the proposed theoretical underpinnings of such effects.

The second focus of this article was on applying these techniques directly to instruction, where they could stimulate students' learning by making them aware of their own cognitive processes or giving them insight into the cognitive processes of more knowledgeable others. Exactly how uncovering ones own cognitive processes with these techniques contributes to learning, should be further investigated. It might be that verbalizing, reviewing, or retrieving process information, evokes a process of reflection by learners on their cognitive processes, thereby making them more aware of what they are doing, and of what they do and do not (yet) know. However, whereas this explanation would be beneficial from an instructional perspective, it might have undesirable effects in research situations: As mentioned before, for many studies, it is crucial for validity reasons that the technique does not interfere with the processes it is to uncover. It might be also be the case though, that verbalizing, reviewing, or retrieving process information better consolidates it in memory (cf. the testing effect that shows that recalling information is found to be more effective for learning than restudying that information; Roediger \& Karpicke, 2006). 
References

Amadieu, F., Van Gog, T., Paas, F., Tricot, A., \& Mariné, C. (2007). Effects of prior knowledge and conceptual map structure on disorientation, cognitive load, and learning. Manuscript submitted for publication.

Atkinson, R. K., Derry, S. J., Renkl, A., \& Wortham, D. (2000). Learning from examples: Instructional principles from the worked examples research. Review of Educational Research, 70, 181-214.

Atkinson, R. K., Renkl, A., \& Merrill, M. M. (2003). Transitioning from studying examples to solving problems: Effects of self-explanation prompts and fading worked-out steps. Journal of Educational Psychology, 95, 774-783.

Ayres, P. (2006). Using subjective measures to detect variations of intrinsic load within problems. Learning and Instruction, 16, 389-400.

Bandura, A. (1986). Social foundations of thought and action: A social cognitive theory. Englewood Cliffs, NJ, Prentice Hall.

Basque, J., \& Lavoie, M-C. (2006). Collaborative concept mapping in education: Major research trends. In A. J. Cañas and J. D. Novak (Eds.) Proceedings of the Second International Conference on Concept Mapping. Retrieved September 20, 2007 from http://cmc.ihmc.us/cmc2006Papers/cmc2006-p192.pdf

Camps, J. (2003). Concurrent and retrospective verbal reports as tools to better understand the role of attention in second language tasks. International Journal of Applied Linguistics, 13, 201-221.

Chandler, P., \& Sweller, J. (1991). Cognitive load theory and the format of instruction. Cognition and Instruction, 8, 293-332.

Chandler, P., \& Sweller, J. (1992). The split-attention effect as a factor in the design of instruction. British Journal of Educational Psychology, 62, 233-246. 
Charness, N., Reingold, E. M., Pomplun, M., \& Stampe, D. M. (2001). The perceptual aspect of skilled performance in chess: Evidence from eye movements. Memory and Cognition, 29, 1146-1152.

Chi, M. T. H., De Leeuw, N., Chiu, M. H., \& LaVancher, C. (1994). Eliciting selfexplanations improves understanding. Cognitive Science, 18, 439-477.

Chi, M. T. H., Glaser, R., \& Farr, M. J. (Eds.). (1988). The nature of expertise. Hillsdale, NJ: Erlbaum.

Cierniak, G., Scheiter, K., \& Gerjets, P. (this issue). Explaining the split-attention effect: Is the reduction of extraneous cognitive load accompanied by an increase in germane cognitive load? Computers in Human Behavior, xx, xxx-xxx.

Cooper, G., \& Sweller, J. (1987). Effects of schema acquisition and rule automation on mathematical problem-solving transfer. Journal of Educational Psychology, 79, 347362.

De Jong, T., \& Ferguson-Hessler, M. G. M. (1986). Cognitive structures of good and poor novice problem solvers in physics. Journal of Educational Psychology, 78, 279-288.

Duchowski, A. T. (2003). Eye tracking methodology: Theory and practice. London: Springer.

Dunston, P. J. (1992). A critique of graphic organizer research. Reading Research \& Instruction, 31, 57-65.

Ericsson, K. A., Charness, N., Feltovich, P. J., \& Hoffman, R. R. (Eds.). (2006). The Cambridge handbook of expertise and expert performance. Cambridge MA: Cambridge University Press.

Ericsson, K. A., \& Simon, H. A. (1993). Protocol analysis: Verbal reports as data (Rev. ed.). Cambridge, MA: MIT Press.

Feldon, D. F. (2007). The implications of research on expertise for curriculum and pedagogy. Educational Psychology Review, 19, 91-110. 
Foltz, P. W. (1996). Latent semantic analysis for text-based research. Behavior Research Methods, Instruments \& Computers, 28, 197-202.

Foltz, P. W., Gilliam, S., \& Kendall, S. (2000). Supporting content-based feedback in online writing evaluation with LSA. Interactive Learning Environments, 8, 111-129.

Graesser, A. C., Wiemer-Hastings, P., Wiemer-Hastings, K., Harter, D., Person, N., \& the Tutoring Research Group (2000). Using Latent Semantic Analysis to evaluate the contributions of students in AutoTutor. Interactive Learning Environments, 8, 129147.

Grant, E. R., \& Spivey, M. J. (2003). Eye movements and problem solving: Guiding attention guides thought. Psychological Science, 14, 462-466.

Haider, H., \& Frensch, P. A. (1999). Eye movement during skill acquisition: More evidence for the information reduction hypothesis. Journal of Experimental Psychology: Learning, Memory and Cognition, 25, 172-190.

Hannafin, M., \& Land, S. (1997). The foundations and assumptions of technology-enhanced student-centered learning environments. Instructional Science, 25, 167-202.

Hegarty, M., \& Just, M. A. (1993). Constructing mental models of machines from text and diagrams. Journal of Memory and Language, 32, 717-742.

Hilbert, T., \& Renkl, A. (this issue). Learning how to use a computer-based concept-mapping tool: examples help. Computers in Human Behavior, $\mathrm{xx}, \mathrm{xxx}-\mathrm{xxx}$.

Holsanova, J., Holmqvist, K., \& Holmberg, N. (2008). Reading information graphics: The role of spatial contiguity and dual attentional guidance. Manuscript submitted for publication.

Horton, P. B., McConney, A. A., Gallo, M., Woods, A. L., \& Hamelin, O. (1993). An investigation of the effectiveness of concept mapping as an instructional tool. Science Education, 77, 95-111. 
Iofciu, T., Zhou, X., Giesbers, B., Rusman, E., Van Bruggen, J., Ceri, S. (2006). State of the art report in knowledge sharing, recommendation and Latent Semantic Analysis. Cooper Consortium Deliverable 3.1

Johnson, T. E., \& O’Connor, D. L. (in press). Measuring team shared understanding using analysis constructed shared mental model methodology. Performance Improvement Quarterly.

Kalyuga, S. (2006a). Rapid cognitive assessment of learners' knowledge structures. Learning and Instruction, 16, 1-11.

Kalyuga, S. (2006b). Assessment of learners' organised knowledge structures in adaptive learning environments. Applied Cognitive Psychology, 20, 333-342.

Kalyuga, S., Ayres, P., Chandler, P., \& Sweller, J. (2003). The expertise reversal effect. Educational Psychologist, 38, 23-32.

Kester, L., Kirschner, P. A., Van Merriënboer, J. J. G., \& Bäumer, A. (2001). Just-in-time information presentation and the acquisition of complex cognitive skills. Computers in Human Behavior, 17, 373-391.

Kuusela, H., \& Paul, P. (2000). A comparison of concurrent and retrospective verbal protocol analysis. American Journal of Psychology, 113, 387-404.

Landauer, T. K., \& Dumais, S. T. (1997). A solution to Plato's problem: The latent semantic analysis theory of acquisition, induction, and representation of knowledge. Psychological Review, 104, 211-240.

Landauer, T. K., McNamara, D. S., Dennis, S., Kintsch, W. (Eds.) (2007). Handbook of Latent Semantic Analysis. Mahwah, NJ: Erlbaum

McDonald, S., \& Stevenson, R. J. (1998). Navigation in hyperspace: An evaluation of the effects of navigational tools and subject matter expertise on browsing and information retrieval in hypertext. Interacting with Computers, 10, 129-142. 
Müller-Kalthoff, T., \& Möller, J. (2003). The effects of graphical overviews, prior knowledge, and self-concept on hypertext disorientation and learning achievement. Journal of Educational Multimedia and Hypermedia, 12, 117-134.

Nesbit, J. C., \& Adesope, O. O. (2006). Learning with concept and knowledge maps: A metaanalysis. Review of Educational Research, 76, 413-448.

Nievelstein, F., Van Gog, T., Boshuizen, H. P. A., \& Prins, F. J. (in press). Expertise-related differences in conceptual and ontological knowledge in the legal domain. European Journal of Cognitive Psychology.

O’Connor, D. L., Johnson, T. E., \& Khalil, M. K. (2004). Measuring team cognition: Concept mapping elicitation as a means of constructing team shared mental models in an applied setting. In A. J. Cañas, J. D. Novak, \& F. M. Gonzalez (Eds.), Concept maps: Theory, methodology, technology. Proceedings of the first international conference on concept mapping (Vol. 1, pp. 487-493). Pamplona, Spain: Public University of Navarra.

Paas, F., \& Van Gog, T. (Eds.) (2006). Recent worked examples research: Managing cognitive load to foster learning and transfer [special issue]. Learning and Instruction, $16(2)$.

Potelle, H., \& Rouet, J. (2003). Effects of content representation and reader's prior knowledge on the comprehension of hypertext. International Journal of Human-Computer Studies, 58, 327-345.

Rayner, K. (1998). Eye movements in reading and information processing: 20 years of research. Psychological Bulletin, 124, 372-422.

Renkl, A. (1997). Learning from worked-out examples: a study on individual differences. Cognitive Science, 21, 1-29. 
Robinson, D. H. (1998). Graphic organizers as aids to text learning. Reading Research and Instruction, 37, 85-105.

Roediger, H. L. \& Karpicke, J. D. (2006). Test-enhanced learning. Taking memory tests improves long-term retention. Psychological Science, 17, 249-255.

Roth, W-M., \& Roychoudhury, A. (1992). The social construction of scientific concepts or the concept map as conscription device and tool for social thinking in high school science. Science Education, 76, 531-557.

Roth, W-M., \& Roychoudhury, A. (1993). The concept map as a tool for the collaborative construction of knowledge: A microanalysis of high school physics students. Journal of Research in Science Teaching, 30, 503-534.

Schmidt-Weigand, F., Kohnert, A., \& Glowalla, U. (2008). A closer look at split visual attention in system-paced and self-paced multimedia instructions. Manuscript submitted for publication.

Schvaneveldt, R. W., Durso, F. T., Goldsmith, T. E., Breen, T. J., Cooke, N. M., Tucker, R. G., \& DeMaio, J. C. (1985). Measuring the structure of expertise. International Journal of Man-Machine Studies, 23, 699-728.

Spector, J. M., Christensen, D. L., Sioutine, A. V., \& McCormack, D. (2001). Models and simulations for learning in complex domains: Using causal loop diagrams for assessment and evaluation. Computers in Human Behavior, 17, 517-545.

Stelmach, L. B., Campsall, J. M., \& Herdman, C. M. (1997). Attentional and ocular movements. Journal of Experimental Psychology: Human Perception and Performance, 23, 823-844.

Stoyanov, S., \& Kirschner, P. (2004). Expert concept mapping method for defining the characteristics of adaptive e-learning: ALFANET project case. Educational Technology Research \& Development, 52(2), 41-56. 
Sweller, J. (1988). Cognitive load during problem solving: Effects on learning. Cognitive Science, 12, 257-285.

Sweller, J., \& Cooper, G. (1985). The use of worked examples as a substitute for problem solving in learning algebra. Cognition and Instruction, 2, 59-89.

Sweller, J., Van Merriënboer, J. J. G., \& Paas, F. (1998). Cognitive architecture and instructional design. Educational Psychology Review, 10, 251-295.

Taylor, K. L., \& Dionne, J. P. (2000). Accessing problem-solving strategy knowledge: The complementary use of concurrent verbal protocols and retrospective debriefing. Journal of Educational Psychology, 92, 413-425.

Tindall-Ford, S., Chandler, P., \& Sweller, J. (1997). When two sensory modes are better than one. Journal of Experimental Psychology: Applied, 3, 257-287.

Trochim, W. M. K. (1989). An introduction to concept mapping for planning and evaluation. Evaluation and Program Planning, 12, 1-16.

Underwood, G., Chapman, P., Brocklehurst, N., Underwood, J., \& Crundall, D. (2003). Visual attention while driving: Sequences of eye fixations made by experienced and novice drivers. Ergonomics, 46, 629-646.

Van Boxtel, C., Van der Linden, J., Roelofs, R., \& Erkens, G. (2002). Collaborative concept mapping. Theory into Practice, 41, 39-46.

Van Gerven, P. W. M., Paas, F., Van Merriënboer, J. J. G., \& Schmidt, H. (2004). Memory load and the cognitive pupillary response in aging. Psychophysiology, 41, 167-174.

Van Gog, T. (2006). Uncovering the problem-solving process to design effective worked examples. Doctoral Dissertation, Open University of The Netherlands, Heerlen, The Netherlands.

Van Gog, T., Ericsson, K. A., Rikers, R. M. J. P., \& Paas, F. (2005). Instructional design for advanced learners: Establishing connections between the theoretical frameworks of 
cognitive load and deliberate practice. Educational Technology Research and Development, 53(3), 73-81.

Van Gog, T., Paas, F., \& Van Merriënboer, J. J. G. (2005). Uncovering expertise-related differences in troubleshooting performance: Combining eye movement and concurrent verbal protocol data. Applied Cognitive Psychology, 19, 205-221.

Van Gog, T., Paas, F., \& Van Merriënboer, J. J. G. (2006). Effects of process-oriented worked examples on troubleshooting transfer performance. Learning and Instruction, 16, 154164.

Van Gog, T., Paas, F., \& Van Merriënboer, J. J. G. (2008). Effects of studying sequences of process-oriented and product-oriented worked examples on troubleshooting transfer efficiency. Learning and Instruction, 18, 211-222..

Van Gog, T., Paas, F., Van Merriënboer, J. J. G., \& Witte, P. (2005). Uncovering the problem-solving process: Cued retrospective reporting versus concurrent and retrospective reporting. Journal of Experimental Psychology: Applied, 11, 237-244.

Van Merriënboer, J. J. G. (1997). Training complex cognitive skills: A four-component instructional design model for technical training. Englewood Cliffs, NJ: Educational Technology Publications.

Van Merriënboer, J. J. G., \& Sweller, J. (2005). Cognitive load theory and complex learning: Recent developments and future directions. Educational Psychology Review, 17, 147177.

Van Someren, M. W., Barnard, Y. F., \& Sandberg, J. A. C. (1994). The think aloud method: A practical guide to modeling cognitive processes. London: Academic Press.

Velichkovsky, B. M. (1995). Communicating attention: Gaze position transfer in cooperative problem solving. Pragmatics \& Cognition, 3, 199-224. 
Wolfe, M. B. W., Schreiner, M. E., Rehder, B., Laham, D., Foltz, P. W., Kintsch, W., \& Landauer, T. K. (1998). Learning from text: Matching readers and texts by latent semantic analysis. Discourse Processes, 25, 309-336.

Wopereis, I. G. J. H., Kirschner, P. A., Paas, F., Stoyanov, S., \& Hendriks, M. (2005). Failure and success factors of educational ICT projects: A group concept mapping approach. British Journal of Educational Technology, 36, 681-684.

Wouters, P., Paas, F., \& Van Merriënboer, J. J. G. (in press). How to optimize learning from animated models? A review of guidelines based on cognitive load. Review of Educational Research.

Zimmerman, B. J., \& Kitsantas, A. (2002). Acquiring writing revision and self-regulatory skill through observation and emulation. Journal of Educational Psychology, 94, 660668. 
Figure Captions

Figure 1. Impression of a cue (screenshot), showing eye movements being replayed over the task (replay of mouse/keyboard actions is not visible in this screenshot) using the Tobii 1750 eye tracker with ClearView software. Participants see a blue dot (located here near the battery on the left side), which indicates their eye fixations, moving across the screen. The gaze trail (i.e., the trail from one fixation to the next) is shown by the line attached to the dot, the fixation duration is shown by increases and decreases in the dot (not visible in this screenshot).

Figure 2. Examples of different types of concept maps. 


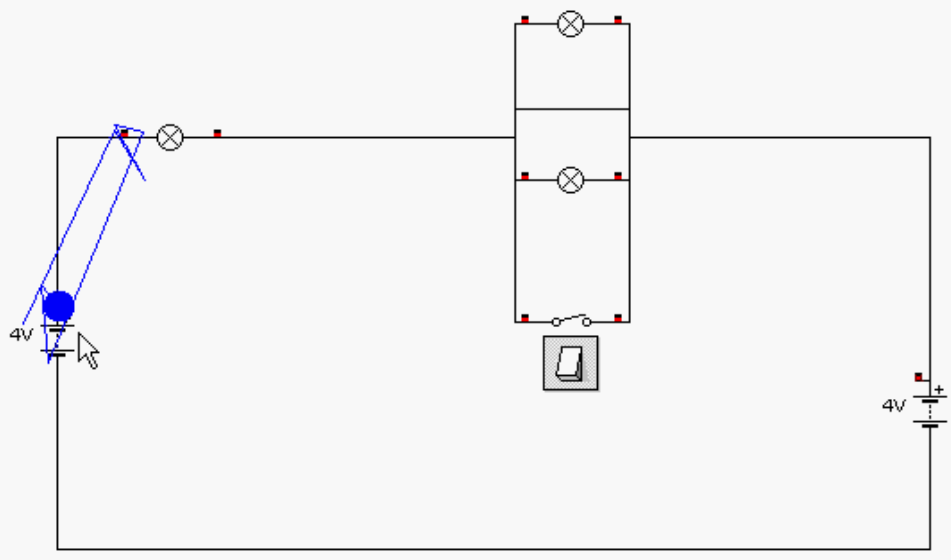



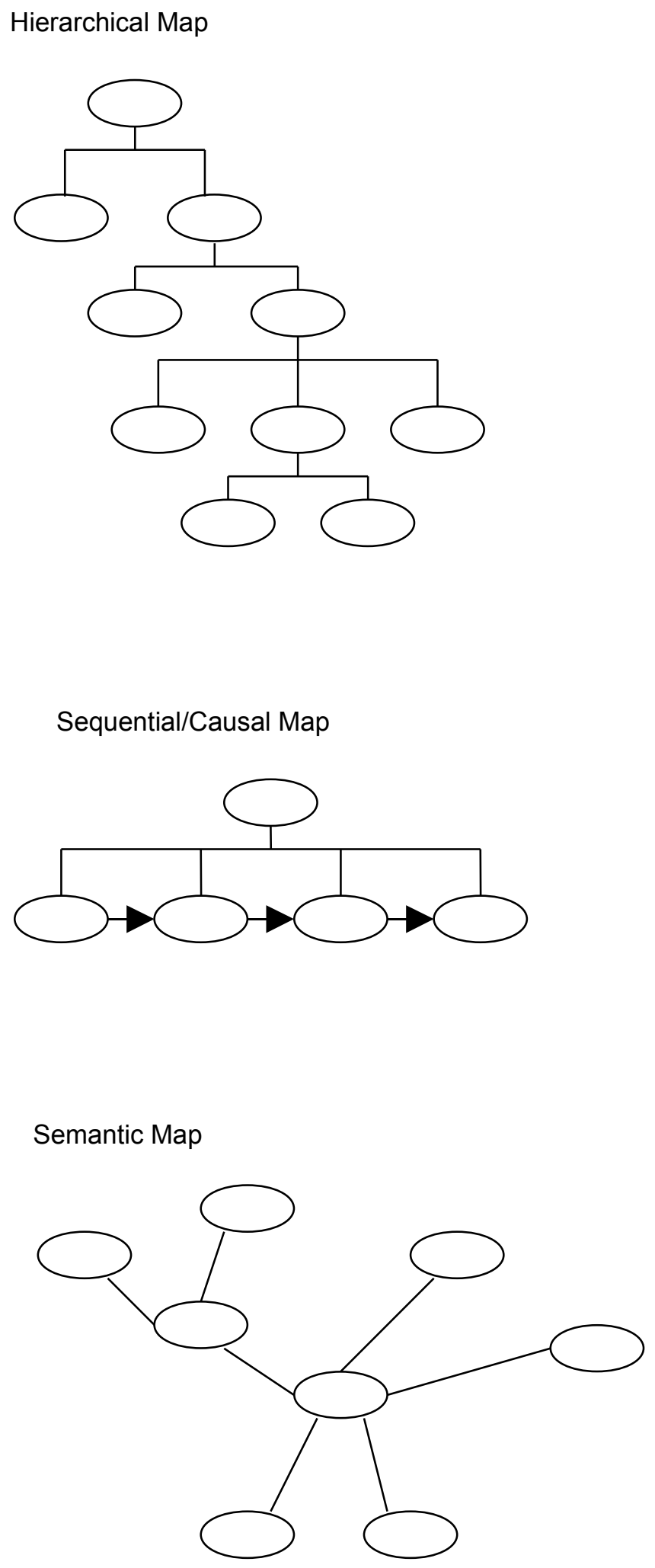